Some of the issued parts are written by world-famous specialists, for example, F. D. Zumpt on medical and veterinary entomology, $H$. Priesner on Thysanoptera, and St von Keler on Mallophaga, and are likely to stand as the most authoritative general accounts in their fields. The general character of the work is scholarly, and most of the parts have extensive and reasonably representative bibliographies, in which non-German works are freely cited. The moderately numerous illustrations, mostly taken from other works, include no coloured and few halftone plates. In the groups so far treated, the taxa are characterized down to the lovel of families, and available information is summarized on such matters as embryology, development, physiologs, behaviour, distribution and the fossil record.

The largest single Lieferung of the twelve is one of 127 pages on the geographical distribution of insects, by H. Franz and M. Beier. This is an immensely complex subject, almost impossible to treat other than oclcctically; up to date information on world-wide distribution in most groups of insects is very difficult to come by, so that most authors dealing with it concentrate their attention on groups of which they have specialist knowledge. Franz and Beier, ignoring Darlington's discussion of the subject in Zoogeography, consider rafting ("Floss-theorie") to have been of little or no importance in insect dispersal across wide scas; they largely follow Gressit on Pacific faunas, but ignore Zimmermann's important work on the Hawaiian insects. Their system of regions and subrcgions is based on "descriptive" rather than "causal" zoogeography, and will not satisfy everybody. A characteristic European bias is shown in their treatment of the Nearctic fauna, which is described as a mixture of Palaearctic and Neotropical elements. Much of the detailed discussion is based on various groups of small terricolous beetles, for example, Pselaphidae and Scydmaenidae, studied by Professor Franz. This is interesting, and will be new to most rcaders, but is open to the objection that information on these forms is still very incomplete as compared, for example, with that on scarabaeoid beetles, which are largely ignored.

In the "special" parts, the new edition follows current tronds in devoting proportionately morc space to general discussions, and less to classification, as compared with the previous one; an extreme example is Schaller's treatment of Collembola, occupying 72 pages, only a little more than three of them devoted to classification, whereas Handlirsch had given three of the eleven pages of his account of tho group to its subdivision. Schaller's account draws attention to an interesting feature of Collembola of which few entomologists are yet likely to be aware - the presenco in thom of giant salivary gland chromosomes like those of Diptera.

It is to be hoped that the task of completing this very important and ambitious work will not be too much for the present generation of German-speaking entomologists; present trends in academic training make it unlikely that their successors would be competent to do so worthily if the task is left to them.

R. A. Crowson

\section{CHIMPANZEE ANATOMY}

\section{Anatomy, Behaviour and Diseases of Chimpanzees}

Edited by G. H. Bourne. (The Chimpanzee, Vol. 1.) Pp. xii +466 . (S. Karger: Basel and New York, 1969.) SFR/DM 115; $\$ 27.60 ; 230 s$.

THIs book is the first volume of a series to be devoted to the chimpanzee. The title could lead the unwary to believe that the work is comprehensive in scope and perhaps more general in its treatment of the subject. This would be an unfortunate error because the rather limited aspects of chimpanzee anatomy, behaviour and diseases that are dealt with in this first volume are written with authority and depth; indeed, some chapters could stand as monographs in their own right.
Following a scholarly account of the history of the discovery of the chimpanzee, Osman-Hill reviews the taxonomy and distribution of the two full species that are generally recognized. This review is valuable and will be of importance to all primate taxonomists from the view. point of source references and for a fair, if conservative, assessment of the present position. This is followed by a section by A. H. Schultz on skeletal morphology and variation that is well written and superbly illustrated. The full page drawing of a chimpanzee skeleton, in knuckle walking pose, will be reproduced in many future texts; it is a fine example of the author's skill.

W. M. Krogman meticulously records data on the growth changes in the skull, face, jaws and teeth, principally from craniometric studies, but some information is included on head measurements taken from X-ray films.

A concise but informative chapter deals with the larynx and the anatomical basis of vocalization. The author concludes that the chimpanzee larynx provides a basis for a "rich vocal production of its own character; but the entire arrangement makes it ontirely impossible to produce the phonetic elements of human speech".

The brain is described in detail from the viewpoint of internal and external morphology by Shantha and Manocha. The descriptions are lengthy and detailed (the brain chapter comprises about one third of the whole book), and contains a number of reference lists that must amount to a bibliography of chimpanzee neurology. The style of writing in this section reeks of theses and is stiff with the Paris Nomenclature, but persistence is well rewarded. Perhaps its principal weakness is that the descriptions are based on the examination of three adult, one infant and one foetal chimpanzee brain. While this is readily admitted, the question of normal variation hardly arises. The volume is completed by essays on the "home raised" Kellogg chimpanzee, nesting patterns, whole body irradiation, malaria and intestinal parasites. From this it can be seen that this first volume is for anatomists because the interests of primate ethologists and pathologists are relatively poorly served.

Undoubtedly this will prove to be an important serios of reference works that should be available to all workers on the chimpanzee. It is well produced on fine paper and should find a place on the shelves of all primate libraries; however, librarians may do well to revert to the mediaeval system of chains if they are to retain their copies.

M. H. DAY

\section{PLANT STRESS}

\section{Environment and Plant Response}

By Michael Treshow. (McGraw-Hill Agricultural Sciences Series.) Pp. $x v+422$. (McGraw-Hill: New York and Maidenhead, April 1970.) $115 s$.

THE title of this book is misleading because one expects it to refer to all aspects of plant response, but the author's preface makes it immediately clear that plant disorders caused by environmental stresses form the principal theme. According to the author, it is an account of "the nature of the environment as a pathogen" - "contrary to common belief, a pathogen technically does not have to be an organism or a virus".

The first part of the book summarizes the author's concept of the physical and biotic environment, and then deals with pathogenic rosponso and diagnosis. Parts two and three present the physical and chemical aspects of the aerial and soil environment, stressing the consequences, for the plant, of deviation from tho norm. The final part, Professor Treshow's home ground, deals with pollution of the terrestrial environment; as a review comprising more than one-third of the book, it is particularly welcome at this time when awarencss of environmental degradation is so rapidly growing. 